Nitin Gupta, MS

Arjun Dass, MS

Vaibhav Saini, MS

Shashikant Anil Pol, MS

Lovekesh Mittal, MBBS

Department of Ear Nose Throat Govt Medical College and Hospital Sector-32

Chandigarh, India
Correspondence: Dr. Nitin Gupta

Associate Professor

Department of E.N.T.

Govt Medical College and Hospital

Sector-32

Chandigarh 160030

India

Phone: +91 9646121704

Email: nitinent123@gmail.com

The authors declared that this represents original material that is not being considered for publication or has not been published or accepted for publication elsewhere, in full or in part, in print or electronic media; that the manuscript has been read and approved by all authors, that the requirements for authorship have been met by each author, and that each author believes that the manuscript represents honest work.

Disclosures: The authors signed disclosures that there are no financial or other (including personal) relationships, intellectual passion, political or religious beliefs, and institutional affiliations that might lead to a conflict of interest.

\section{Extranasopharyngeal Angiofibroma: A Diagnostic Dilemma}

\author{
ABSTRACT \\ challenges involved.

\section{Methods:} \\ Design: Case Report \\ Setting: Tertiary Teaching Hospital and Medical School \\ Patients: Two
}

Objective: To report two cases of extranasopharyngeal angiofibroma, highlighting the diagnostic

Results: A 13-year-old boy who presented with epistaxis and a vascular mass on the posterior nasal septum that enhanced on contrast-enhanced computed tomography (CECT), and a 3-year-old boy who presented with dysphagia and mild respiratory difficulty, with a large nasooropharyngeal mass arising from the soft palate on physical and x-ray examination that could not be corroborated because stridor developed during sedation for CECT, both underwent endoscopic tumor excision.

Conclusion: As illustrated in these cases, atypical presentations of extranasopharyngeal angiofibromas can pose a considerable diagnostic and surgical challenge for clinicians.

Keywords: angiofibroma: classification; diagnosis; diagnostic imaging; extranasopharyngeal

Angiofibromas are vascular tumors that are frequently observed in adolescent males and are the most common benign tumors of the nasopharynx. ${ }^{1}$ Extranasopharyngeal angiofibromas are very rare tumors ${ }^{2}$ that can present in either sex, different age groups and varying locations compared to classical angiofibromas., ${ }^{3,4}$ It has been suggested that extranasopharyngeal angiofibroma be considered as a separate entity ${ }^{2}$ or that tumors with different characteristics from those of classical angiofibroma be referred to as 'atypical angiofibroma.5 Further to a previous report of two cases, ${ }^{6}$ we present two more such cases. 


\section{CASE REPORTS}

Case 1

A 13-year-old boy presented in hospital with the chief complaint of acute-onset, profuse, intermittent, spontaneously resolving bleeding from the right nasal cavity for the past 3 days. There was no history of trauma, fall or deranged coagulopathy. He had a total of 3 episodes of such bleeding before consult.

He had pallor on general physical examination. Anterior rhinoscopy revealed blood clots in the anterior right nasal cavity with a polypoidal mass in the posterior part. Blood stains were also visualized over the posterior pharyngeal wall. He was admitted for diagnostic nasal endoscopy under general anaesthesia. Routine investigations prior to procedure revealed low hemoglobin of $7.6 \mathrm{gm} \%$ for which 3 units of cross-matched packed red blood cells were transfused.

Plain computed tomography showed a mass in nasopharynx with a normal sphenopalatine area while contrast computed tomography revealed an enhancing lesion in the posterior part of the septum. (Figure 1) With a differential diagnosis of bleeding polyps of the septum and extranasopharyngeal juvenile angiofibroma, endoscopic excision was planned.

Intraoperative findings revealed a $1.5 \times 1 \mathrm{~cm}$ polypoidal mass which was attached to posterior part of the right septum. (Figure 2) The mass was completely excised and the site of origin cauterized. Histopathological examination revealed a tumor composed of abundant thin-walled variably sized blood vessels lined by a single layer of endothelium. (Figure 3) He was discharged on the third postoperative day and has remained disease-free on regular follow-up for 6 months.

\section{Case 2}

A 3-year-old boy presented in hospital with the chief complaint of acute-onset difficulty swallowing both solids and liquids that persisted for the last 15 days with no aggravating or relieving factors. There was also mouth-breathing and intermittent noisy breathing.

Examination of the oral cavity revealed a single, smooth, pinkish, non-pulsatile, ovoid-polypoidal mass of approximately $4 \times 3 \mathrm{~cm}$ which seemed to arise from the nasopharynx. A soft tissue neck lateral $x$-ray of the neck was suggestive of an homogenous mass arising from the nasopharynx reaching up to the oropharynx. (Figure 4)

As he was being sedated for contrast enhanced computed tomography, he started having difficulty in breathing and was intubated. He was transferred to the operating theatre under bag and mask ventilation for emergent surgery.

Intraoperative findings were suggestive of a nasopharyngeal mass pushing the uvula into the oropharynx. (Figure 5) The mass actually arose from the posterior part of the soft palate and uvula. It was completely excised and delivered perorally. Histopathological examination revealed blood vessels lined by a single layer of endothelial cells. No stromal atypia was seen. (Figure 6) He was discharged on the fifth post-operative day.
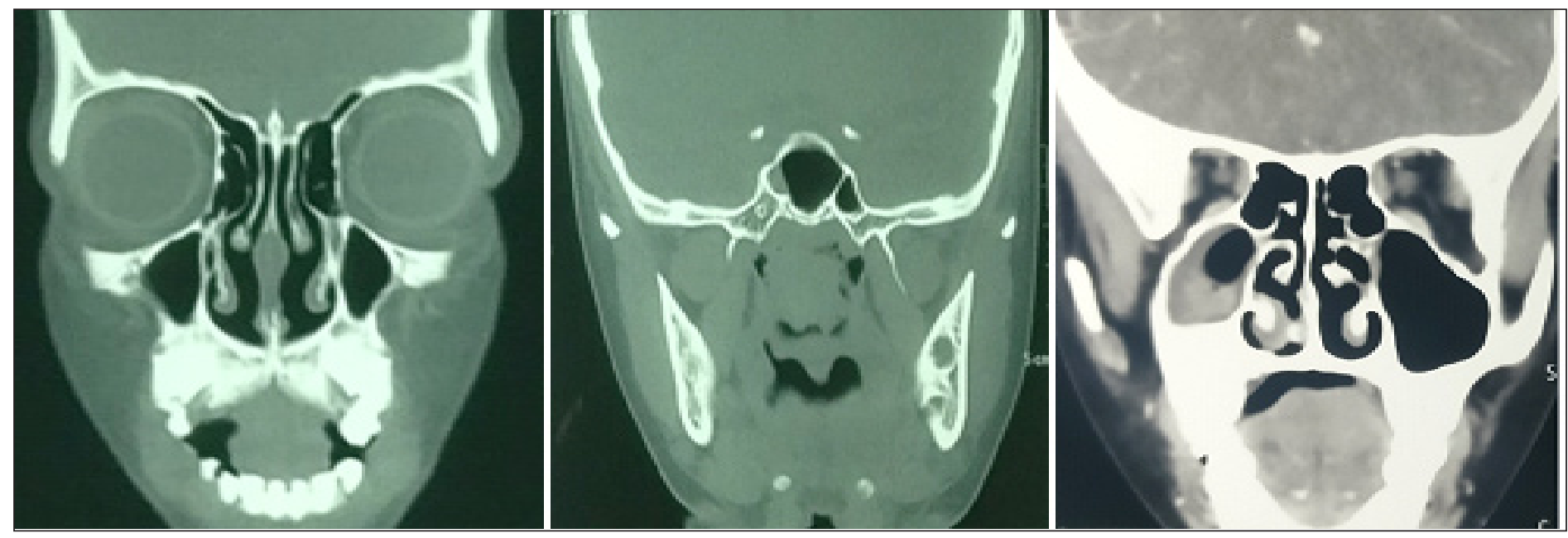

Figure 1. Plain CT showed a normal sphenopalatine area while contrast CT revealed an enhancing lesion in the posterior septum on the right. 
CASE REPORTS

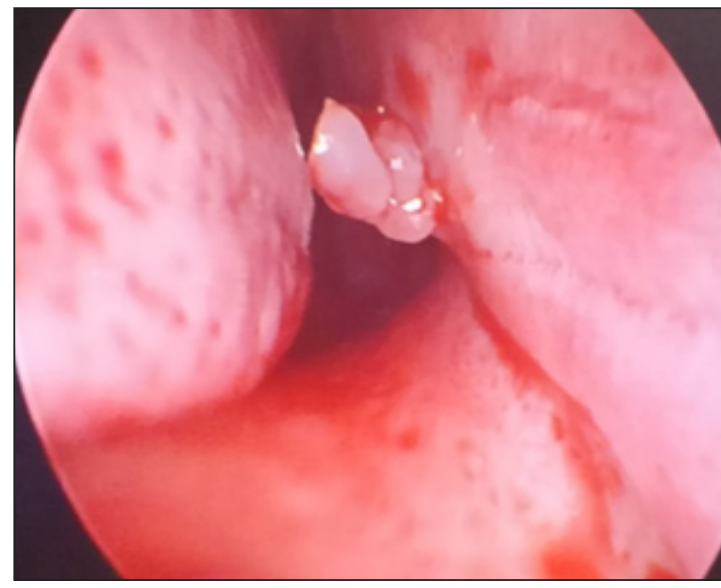

Figure 2. Intraoperative findings of a $1.5 \times 1 \mathrm{~cm}$ polypoidal mass attached to the posterior right side of the septum.

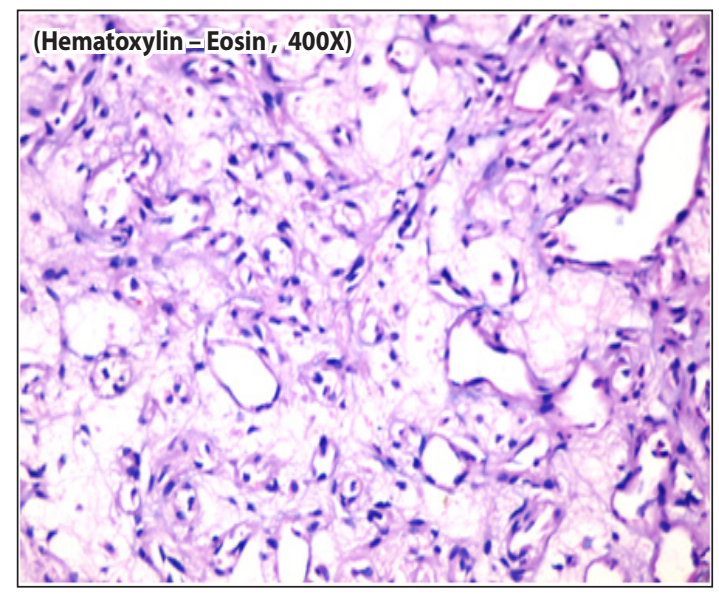

Figure 3. Histopathological examination (Hematoxylin - Eosin, $400 \mathrm{x}$ ), revealed tumor composed of abundant thin-walled variably sized blood vessels lined by a single layer of endothelium.



Figure 4. Soft tissue lateral neck x-ray suggestive of an homogenous mass arising from the nasopharynx reaching down to the oropharynx.

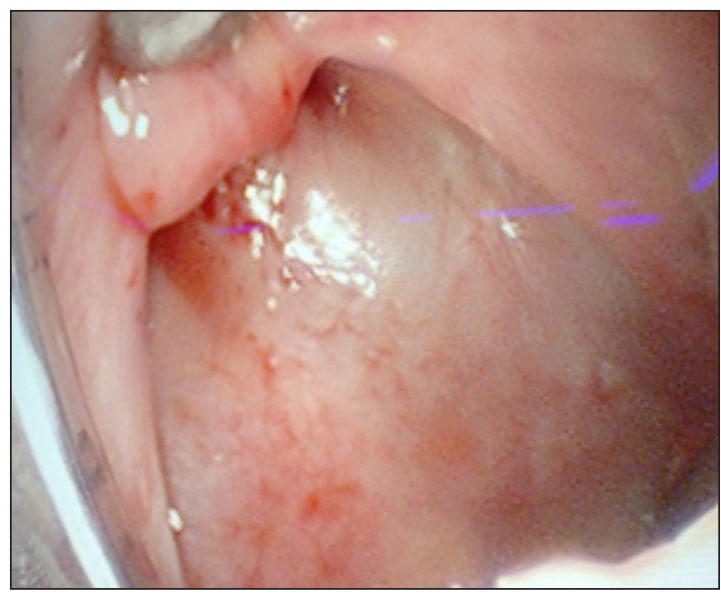

Figure 5. Intraoperative photo showing the mass pushing the uvula and extending to the oropharynx.

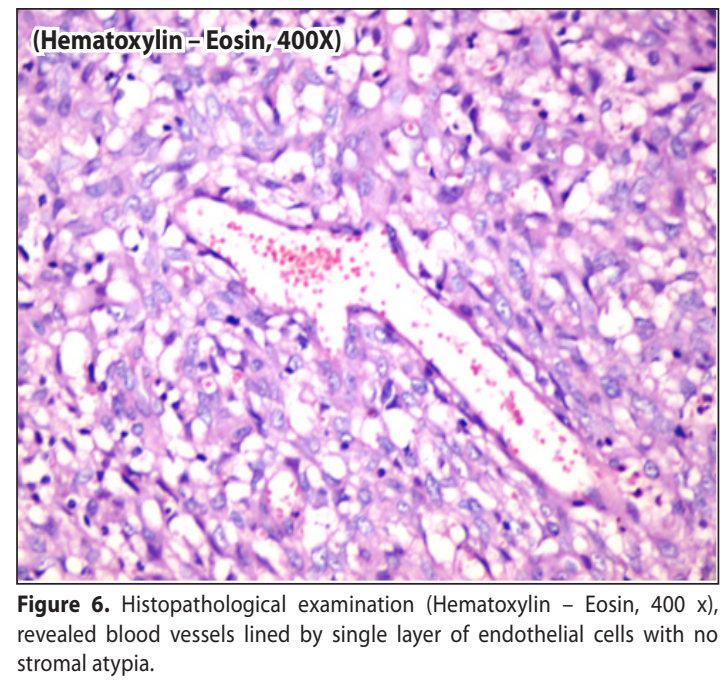

\section{DISCUSSION}

Angiofibroma is the most common tumor in the nasopharynx, making up $0.5 \%$ of all head and neck tumors and is typically found in young males in the first two decades. ${ }^{1,7}$ More recently, the term extranasopharyngeal angiofibroma has been applied to vascular, fibrous nodules occurring outside the nasopharynx that do not arise from the vicinity of the sphenopalatine foramen or pterygoid plates. ${ }^{2,5}$ Compared to those with nasopharyngeal angiofibromas, patients with extra-nasopharyngeal angiofibroma differ in presentation. These patients are older, both sexes can be affected, symptoms develop more quickly and hypervascularity is less common. ${ }^{4}$ Angiofibromas presenting with at least one of the following criteria such as origin or location other than nasopharynx, presenting complaints other than nasal obstruction or epistaxis, age younger than seven or older than 25 , female sex, atypical histopathology and multifocality were considered 


\section{CASE REPORTS}

as 'atypical'.5

The mean age of presentation of the tumor in extranasopharyngeal sites is 22 years and the male to female ratio is roughly $3: 1{ }^{1,6}$ In contrast, nasopharyngeal angiofibroma presents almost exclusively in adolescent males with a mean age range between 14 and 17 years and female presentation is very rare. ${ }^{4}$ It is unclear why this discrepancy in the age of presentation and sex predilection exists between the two different types of angiofibromas. Unlike previous reports, ${ }^{5}$ our patients were 13 and 3 years old. Our 2 previously reported cases had patients who were 28 and 12 years old, respectively. ${ }^{6}$

Extra-nasopharyngeal angiofibromas most commonly take their origin from maxillary sinus. ${ }^{7}$ Other primary extra-nasopharyngeal sites reported are ethmoid and sphenoid sinuses, nasal septum, frontal recess, middle and inferior turbinates, tonsil, parapharyngeal space, ear, trachea, larynx, middle cranial fossa, infratemporal fossa, tonsil, retromolar region and conjunctiva. ${ }^{8}$ Trinidad et al. have reported a case of extranasal angiofibroma arising from the vocal cord..$^{8}$ In our cases the mass was seen arising from the posterior septum and oropharynx, respectively. To the best of our knowledge, based on a search of the English literature in MEDLINE(PubMed), EMBASE, Scopus and Google Scholar using the keywords "angiofibroma," "extranasopharyngeal angiofibroma," "juvenile angiofibroma," "atypical angiofibroma," we could not find no other reports of an angiofibroma arising from the soft palate and uvula.

Contrast enhanced CT scan (CECT) and magnetic resonance imaging (MRI) are the key investigations to determine tumor site and extension, with special attention being focused on skull base involvement, intracranial spread and relationship to important vascular and neurologic structures. ${ }^{9}$ While bone erosion can be more easily revealed by $C T$ scan, $\mathrm{MRI}$ is adequate in demonstrating cortical erosion and cancellous replacement by tumour. ${ }^{9,10}$ T1-weighted MRI show a typical "salt and pepper" appearance caused by the increased vascularity of the tumour. ${ }^{10,11}$ Alvi et al. considered CT scan to be sufficient for the diagnosis of extranasopharyngeal angiofibroma, as it clearly delineates and identifies the tumour. ${ }^{12}$ Extreme caution should be exercised while performing CT scan in patients with an already compromised airway. This caution is even more imperative in paediatric patients as sedating the child can further precipitate respiratory embarrassment in narrow airways of children, as was seen in our case. An intubation and resuscitation trolley should always kept on standby in such cases.

Surgical excision of the mass is the treatment of choice and recurrence rate is generally low. Both of our cases were operated endoscopically. The decision to perform JNA resection endoscopically should be based on the experience and skill of the surgeon as well as the extent of the tumour (i.e. the lateral extent of the tumour must be accessible endoscopically). ${ }^{13}$ Tumours extending to the lateral wall of frontal sinuses, intracranially or reaching up to skin are not suitable candidates for endoscopic excision. ${ }^{5,14}$ The surgeon must also be willing and capable to convert to an open approach if necessary. ${ }^{14}$ It has been suggested that tumours involving the ethmoid, maxillary, or sphenoid sinus, the sphenopalatine foramen, nasopharynx, or pterygomaxillary fossa and having limited extension into the infratemporal fossa are amenable to endoscopic resection. ${ }^{14}$ Complete excision is therefore undertaken for both therapeutic and diagnostic purposes. ${ }^{14}$

In closing, our review of the literature and experience with previously reported cases, teach us that although extranasopharyngeal angiofibroma is a rare entity, it should be kept in mind as a differential diagnosis of a nasal mass irrespective of the status of the vascularity, age or sex of the patient until histopathologically proven. Extranasopharyngeal sites should be regarded as potential, though exceptional, places of origin for these neoplasms. As illustrated in these cases, atypical presentations of extranasopharyngeal angiofibromas can pose a considerable diagnostic and surgical challenge for clinicians.

\section{REFERENCES}

1. Windfuhr JP, Remmert S. Extranasoparyngeal angiofibroma: etiology, incidence and management. Acta Otolaryngol 2004 Oct; 124(8): 880-9. DOI: 10.1080/00016480310015948; PMID: 15513521

2. De Vincentiis G, Pinelli V. Rhinopharyngeal angiofibroma in the pediatric age group. Clinical -statistical contribution. Int J Pediatr Ororhinolaryngol. 1980 Jun; 2(2):99-122. PMID: 6323331.

3. Akbas Y, Anadolu Y. Extranasopharyngeal angiofibroma of the head and neck in women. Am J Otolaryngol. 2003 Nov-Dec; 24(6):413-4. PMID: 14608576.

4. Peloquin L, Klossec JM, Basso-Brusa F, Gougeon JM, Toffel PH, Fontanel JP. A rare case of nasopharyngeal angiofibroma in a pregnant woman. Otolaryngol Head Neck Surg, 1997 Dec;117(6), pp. S111-4. DOI: 10.1016/S0194-59989770074-3 PMID: 9419120.

5. Celik B, Erisen L, Saraydaroglu O, Coskun H. Atypical angiofibroma: a report of four cases. Int J Pediat Otorhinolaryngol 2005 Mar; 69(3): 415-421. DOI: 10.1016/j.ijporl.2004.10.007; PMID: 15733604.

6. Singhal SK, Gupta N, Verma H, Dass A, Kaur A. Extranasopharyngeal angiofibroma: Report of two cases. Egyptian Journal of Ear, Nose, Throat and Allied Sciences. 2014 Mar; 15(1):73-76.https:// doi.org/10.1016/j.ejenta.2013.12.002.

7. Nomura K, Shimomura A, Awataguchi T, Murakami K, Kobayashi T. A case of angiofibroma originating from the inferior nasal turbinate. Auris Nasus Larynx 2006 Jun; 33(2):191-3. DOI: 10.1016/j.anl.2005.09.004; PMID: 16310998.

8. Trinidad CAJ, David MJC, Chua AH. Extranasopharyngeal angiofibroma of the larynx. Philipp J Otolaryngol Head Neck Surg. 2010 Jan-Jun; 25(1): 23-25.

9. Mehmet A, Orhan S, Supni M. Juvenile nasopharyngeal agiofibroma : Radiological Evaluation \& preoperative Embolization. KBB Forum. 2006; 5(1): 58-61.

10. Suhick B, Kahle G. Radiological findings in angiofibroma. Acta Radiol. 2000 Nov; 41(6):585-93. PMID: 11092480 .

11. Maroldi R, Berlucchi M, Farina D, Tomenzoli D, Borghesi A, Pianta L. Benign neoplasm and tumor-like lesions. In: Maroldi R, Nicolai P (editors). Imaging in treatment planning for sinonasal diseases. 2005. Berlin, Heidelberg, New York: Springer Verlag. p. 107-58.

12. Alvi A, Myssiorek D, Fuchs A. Extranasopharyngeal angiofibroma. J Otolaryngol. 1996 Oct; 25(5):346-8. PMID: 8902697.

13. Harrison DF. The natural history, pathogenesis, and treatment of juvenile angiofibroma Personal experience with 44 patients. Arch Otolaryngol Head Neck Surg. 1987 Sep; 113 (9):936 42. PMID: 3038146.

14. Hazarika P, Nayak DR, Balakrishnan R, Raj G, Pillai S. Endoscopic and KTP laser-assisted surgery for juvenile nasopharyngeal angiofibroma. Am J Otololaryngol. 2002 Sep-Oct; 23(5): 282-286. PMID: 12239693. 